\title{
Physiological and Behavioral Manifestations of Children and Teenagers with Down Syndrome During the Dental Appointment: A Comparative Cross-Sectional Study
}

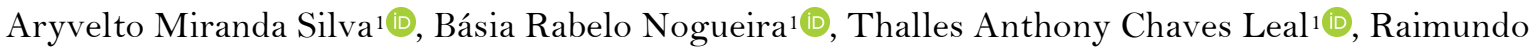 \\ Rosendo Prado Júnior ${ }^{1}\left(\mathbb{D}\right.$, Regina Ferraz Mendes ${ }^{1}(\mathbb{D}$
}

${ }^{1}$ Postgraduate Program in Dentistry, Federal University of Piauí, Teresina, PI, Brazil.

Author to whom correspondence should be addressed: Aryvelto Miranda Silva, Postgraduate Program in Dentistry, Federal University of Piaú, Campus Ministro Petrônio Portella, SG5, Ininga, Teresina, Piaú, Brazil. 64049-550. Phone: +5586998632961. E-mail: aryveltomirand@gmail.com.

Academic Editors: Alessandro Leite Cavalcanti and Wilton Wilney Nascimento Padilha

Received: 18 March 2019 / Accepted: 30 September 2019 / Published: 25 October 2019

How to cite this article: Silva AM, Nogueira BR, Leal TAC, Prado Júnior R, Mendes RF. Physiological and behavioral
manifestations of children and teenagers with down syndrome during the dental appointment: a comparative cross-
sectional study. Pesqui Bras Odontopediatria Clín Integr. 2020; 20:e4658. https://doi.org/10.1590/pboci.2020.006

\begin{abstract}
Objective: To measure the heart rate $(\mathrm{HR})$ and the behavior of children and teenagers with Down Syndrome (DS) during the dental appointment. Material and Methods: Two groups $(\mathrm{n}=52)$, of both genders, aged 2-14 years, matched by age group were formed: study group (SG) - individuals with DS and control group (CG) - normotypical school children. The participants were submitted to clinical examination and prophylaxis. An oximeter was used to measure the HR at five moments of the dental consultation: before entering the practice room (To), when sitting in the dental chair (T1), during the clinical examination (T2), during prophylaxis (T3) and immediately after prophylaxis (T4). Behavior, classified according to the Frankl Scale, was observed at T3. Mann Whitney, Kruskal-Wallis, Dunn and Pearson's Chi-square tests were used to analyze and compare variables (significance level at $5 \%$ ). Results: In SG, a significant difference in HR was observed according to the moment of dental appointment $(\mathrm{p}<0.001 \mathrm{SG}$; 0.3385 CG). The highest HR value in SG was observed at T3 (median 110.00; IIQ 96.00-124.00), the only moment significantly different $(\mathrm{p}<0.001)$ from HR values for CG. A difference in behavior between groups $(p<0.001)$ was also observed. Conclusion: HR of individuals with DS varied throughout the dental appointment, and they also had a higher prevalence of uncooperative behavior.
\end{abstract}

Keywords: Down Syndrome; Appointments and Schedules; Heart Rate; Cooperative Behavior. 


\section{Introduction}

Dental extraction and/or the sensation of pain has commonly been associated with the dental appointment [1]. Therefore, physiological changes - such as an increase in heart rate or blood pressure - and behavioral changes in patients due to dental anxiety are commonly observed during dental appointments [2]. Dental anxiety is a persistent fear and manifestation of exacerbated reactions to dental procedure stimuli [3]. Between 6 to $20 \%$ of children suffer from dental anxiety and they tend to avoid the dentist or are barely cooperative, making it difficult to complete procedures [3-5]. This can be of special concern in children with Down Syndrome.

Down Syndrome (DS) is an autosomal chromosomal anomaly resulting from the trisomy of chromosome 21 [6]. Among DS-related conditions, cardiac abnormalities are frequent, including Tetralogy of Fallot, patent ductus arteriosus, and septal defects [6]. Congenital cardiac abnormalities require special precautions and are associated with complications such as congestive cardiac death, heart failure, thromboembolism and complications of non-cardiac surgery [6,7].

Due to the prevalence of people with cardiac conditions associated with genetic conditions and/or dental anxiety, the inclusion of blood pressure and heart rate measurements as a routine practice is extremely important in the professional routine of dentists [8,9].

The purpose of this study was to measure the heart rate and behavior of children and teenagers with DS during the dental appointment. We tested the null hypothesis that there is no difference in behavioral and heart rate variations in children and teenagers with or without DS during the dental appointment.

\section{Material and Methods}

Study design and Participants

A comparative cross-sectional observational study was performed. The study population consisted of two groups. The study group (SG) consisted of 52 children and teenagers with DS, 4 to 14 years old, attending the Integrated Center for Special Education (CIES), in Teresina, Piauí, Brazil. The control group (CG) consisted of normotypical children and teenagers in the same age group, enrolled in municipal public schools in the same city.

For SG, all the individuals who were regularly enrolled at CIES at the beginning of the data collection with a medical diagnosis of DS were considered eligible. We did not include those individuals with other developmental disorders associated with DS. The presence of any comorbidity, the use of medication that has an implication for the cardiovascular system and the presence of cardiovascular diseases were also considered as non-eligibility criteria.

CG also consisted of 52 children aged 4 to 14 years, who did not present any cardiovascular disease. They were randomly selected from a school attendance list provided by the six schools, which had been previously selected at random from the public schools in Teresina, Brazil. All participants had already undergone dental consultations prior to inclusion in the study.

\section{Procedures and Data Collection Instruments}

Caregivers of the participants answered a questionnaire about socioeconomic data and habits related to oral health at the moment of care. As a preparation for the data collection, caregivers were instructed to inform the participants that they would go to the dentist for a dental session. Due to the extremely hot local weather conditions, all the consultations were carried out in a room equipped with air conditioning, so that any 
weather interference factors could be controlled during data collection. Data collection was carried out between April 2015 and October 2016.

The heart rate $(\mathrm{HR})$ of the study participants was measured using an oximeter (Finger Pulse Oximeter Model - Fingertip, China), that was placed on the left index finger of the participant and used according to the manufacturer's instructions. Changes in the lightwave spectrum through the finger during pulsation of blood generate a measure of blood oxygenation and pulse rate sent to the oximeter. Heart rate is measured in beats per minute (bpm).

HR was recorded at five moments: one minute before the procedure (To), one minute after sitting in the dental chair ( $\mathrm{T} 1)$, one minute after the beginning of the clinical examination (T2), one minute after the beginning of the prophylaxis (T3) and one minute after the end of prophylaxis (T4) [10,11].

The participant's behavior was assessed during the dental prophylaxis (T3) using the FranklBehavior-Rating-Scale. This scale classifies behavior as "definitely negative" (1), "negative" (2), "positive" (3) and "definitely positive" (4) [12]. The participant was considered uncooperative (group G1) when their behavior was "definitely negative" and "negative" and was considered cooperative if their behavior was classified as "positive" and "definitely positive" (group G2).

The clinical examination of the oral cavity was performed in a dental chair with the use of artificial light from the reflector, a flat mouth mirror and a number 5 dental probe, according to the recommendation by the World Health Organization [13]. The procedure consisted of a prophylaxis using a Robinson's brush and pumice and prophylactic paste. A time of 5 min was standardized to perform the procedure.

SG data collection was carried out in a dental room at CIES. For CG, data collection took place at a health unit dental office near the school where they were recruited. For both groups, participants already knew the data collection location and had previously undergone a dental appointment.

The examiner was trained on the use of oximeter and behavioral analysis and calibrated regarding the use of the Frankl Scale. Intra-examiner (1.00) and inter-examiner agreement (0.85) Kappa scores, resulting from the agreement with a specialist in Dentistry for patients with special needs, were considered acceptable. The primary and secondary outcomes of the study were the changes in heart rate and behavioral changes during the dental procedure, respectively.

\section{Statistical Analysis}

Initially, a descriptive analysis of the data was performed. The heart rate normality distribution was tested using the Shapiro-Wilk test. As the data did not present normal distribution $(\mathrm{p} \leq 0.011)$, nonparametric statistical tests were used. Mann-Whitney test was applied for the analysis of the median HR intergroup. For the intragroup analysis of the moments of the dental appointment, Kruskal-Wallis and Dunn tests were applied. A Chi-square test was applied to compare the frequency of behavior types and socioeconomic characteristics between the groups. All analyses were conducted using the Statistical Package for Social Sciences (SPSS for Windows, version 21.0, SPSS Inc. Chicago, IL, USA), with significance level $\leq$ 0.05.

Ethical Aspects

This study was approved by the review board of the Federal University of Piauí (CAAE 17993013.4.0000.5214). Its development followed the ethical recommendations of the Declaration of Helsinki. The inclusion of study participants was consented to by the signature of informed consent and assignment statements. 


\section{Results}

No difference was observed between groups regarding socio-demographic characteristics, including gender, age group, years of parental study and family income, validating the pairing between the participants of the two groups by age (Table 1).

Table 1. Socioeconomic data of children and teenagers with or without Down Syndrome.

\begin{tabular}{|c|c|c|c|}
\hline Variables & $\begin{array}{c}\mathbf{S G}^{\mathbf{a}} \\
\mathrm{N}(\%)\end{array}$ & $\begin{array}{c}\mathbf{C G}^{\mathbf{b}} \\
\mathrm{N}(\%)\end{array}$ & p-value ${ }^{*}$ \\
\hline \multicolumn{4}{|l|}{ Gender } \\
\hline Male & $23(44.2)$ & $30(57.7)$ & 0.170 \\
\hline Female & $29(55.8)$ & $22(42.3)$ & \\
\hline \multicolumn{4}{|l|}{ Age Range } \\
\hline $2-6$ years & $25(48.1)$ & $25(48.1)$ & 1.000 \\
\hline $7-14$ years & $27(51.9)$ & $27(51.9)$ & \\
\hline \multicolumn{4}{|l|}{ Mother's Schooling } \\
\hline$\leq 11$ years & $11(21.2)$ & $16(30.8)$ & 0.263 \\
\hline$>11$ years & $41(78.8)$ & $36(69.2)$ & \\
\hline \multicolumn{4}{|l|}{ Father's Schooling } \\
\hline$\leq 11$ years & $21(42.9)$ & $27(58.7)$ & 0.123 \\
\hline$>11$ years & $28(57.1)$ & $19(41.3)$ & \\
\hline \multicolumn{4}{|l|}{ Per Capita Income } \\
\hline$\leq 1 \mathrm{MW}$ & $38(73.1)$ & $34(65.4)$ & 0.395 \\
\hline$>1 \mathrm{MW}$ & $14(26.9)$ & $18(34.6)$ & \\
\hline
\end{tabular}

The intergroup analysis revealed that $\mathrm{HR}$ values for $\mathrm{SG}$ were higher than those for CG at T3 (SG median 110.00; CG median 91.50 - p<0.001). The intragroup analysis showed (Figure 1) that there were differences in HR at different moments only for SG.
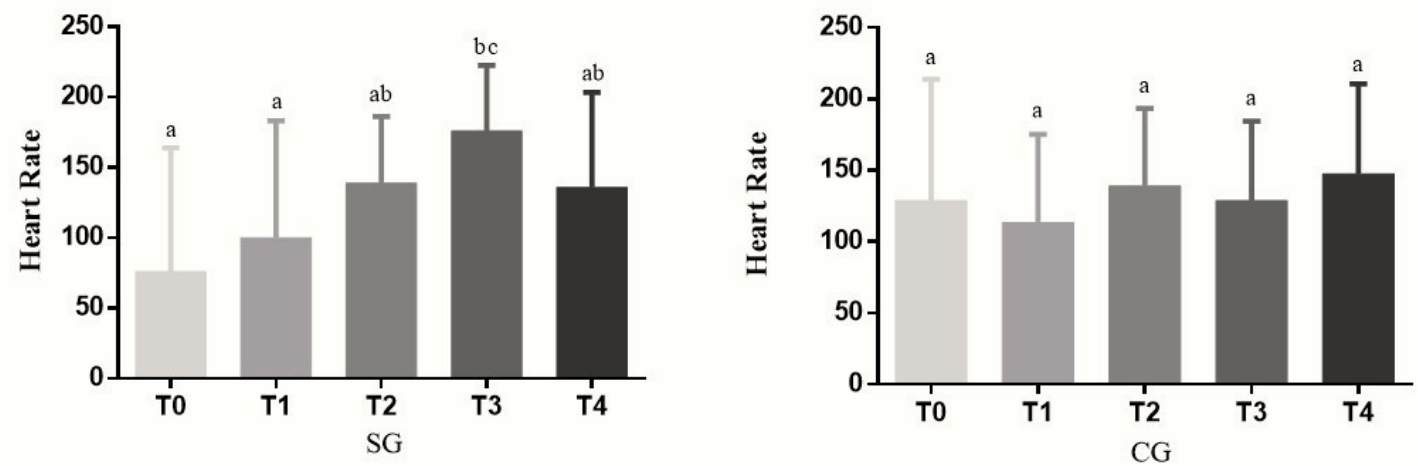

Kruskal-Wallis and post-hoc Dunn test $(\mathrm{p}<0.05)$. Different letters in the bars mean statistically significant differences.

Figure 1. Heart rate analysis during five moments of dental appointment.

Table 2 shows that, for participants with DS, there was no difference in the HR values measured during the five moments of the dental appointment, when the group was classified according to behavior and gender.

The frequency of participants, according to their behavior, can be observed in Table 3 . In the study group, $59.6 \%$ of the participants presented uncooperative behavior. In the control group, $92.3 \%$ had 
cooperative behavior. There was a significant difference between groups regarding the type of behavior of the participant, whether cooperative or uncooperative, during the dental procedure $(\mathrm{p}<0.001)$.

Table 2. The heart rate of individuals with Down Syndrome during dental appointment according to their gender and type of behavior.

\begin{tabular}{|c|c|c|c|c|c|c|}
\hline \multirow{3}{*}{$\begin{array}{c}\text { Dental } \\
\text { Appointment }\end{array}$} & \multicolumn{2}{|c|}{ Female } & \multicolumn{4}{|c|}{ Male } \\
\hline & $\begin{array}{l}\text { Uncooperative } \\
\qquad(\mathrm{N}=16)\end{array}$ & $\begin{array}{c}\text { Cooperative } \\
(\mathrm{N}=13)\end{array}$ & p-value* & $\begin{array}{l}\text { Uncooperative } \\
\qquad(\mathrm{N}=15)\end{array}$ & $\begin{array}{l}\text { Cooperative } \\
(\mathrm{N}=8)\end{array}$ & p-value \\
\hline & \multicolumn{2}{|c|}{ Median (IIQ) } & \multicolumn{4}{|c|}{ Median (IIQ) } \\
\hline To & $\begin{array}{c}95.50 \\
(67.25-16.75)\end{array}$ & $\begin{array}{c}83.00 \\
(61.00-95.00)\end{array}$ & 0.184 & $\begin{array}{c}85.00 \\
(75.00-111.00)\end{array}$ & $\begin{array}{c}91.00 \\
(76,00-109.25)\end{array}$ & 0.825 \\
\hline $\mathrm{T} 1$ & $\begin{array}{c}102.00 \\
(71.00-14.25)\end{array}$ & $\begin{array}{c}86,00 \\
(75.00-97.00)\end{array}$ & 0.503 & $\begin{array}{c}89.00 \\
(82.00-116.00)\end{array}$ & $\begin{array}{c}91.50 \\
(81.50-109.25)\end{array}$ & 0.776 \\
\hline $\mathrm{T} 2$ & $\begin{array}{c}97.50 \\
(79.50-25.75)\end{array}$ & $\begin{array}{c}105.00 \\
(85.50-10.00)\end{array}$ & 0.983 & $\begin{array}{c}110.00 \\
(87.00-116.00)\end{array}$ & $\begin{array}{c}99.00 \\
(91.00-107.50)\end{array}$ & 0.681 \\
\hline T3 & $\begin{array}{c}116.00 \\
(93.50-24.75)\end{array}$ & $\begin{array}{c}113.00 \\
(87.50-19.50)\end{array}$ & 0.449 & $\begin{array}{c}115.00 \\
(98.00-141.00)\end{array}$ & $\begin{array}{c}98.00 \\
(93.00-109.25)\end{array}$ & 0.213 \\
\hline $\mathrm{T} 4$ & $\begin{array}{c}87.50 \\
(75.25-27.50)\end{array}$ & $\begin{array}{c}99.00 \\
(83.50-15.50)\end{array}$ & 0.880 & $\begin{array}{c}101.00 \\
(79.00-122.00)\end{array}$ & $\begin{array}{c}96.00 \\
(90.00-109.25)\end{array}$ & 0.776 \\
\hline
\end{tabular}

To - Before consultation; T1 - When sat on dental chair; T2 - During clinical examination; T3 - During prophylaxis; T4 - Immediately after procedure; *Mann-Whitney's Test.

Table 3. Distribution of the sample according to behavioral analysis during the dental appointment.

\begin{tabular}{cccc}
\hline \multirow{2}{*}{ Groups } & \multicolumn{2}{c}{ Behavior } & \\
& Uncooperative & Cooperative & p-value* \\
& $\mathrm{N}$ & $\mathrm{N}$ & \\
\hline $\mathrm{SG}^{\mathrm{a}}$ & 31 & 21 & $<0.001$ \\
$\mathrm{CG}^{\mathrm{b}}$ & 4 & 48 & \\
\hline
\end{tabular}

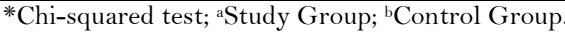

A post-hoc analysis was performed to calculate the power of the test, obtaining a power of 1.00, which means that the probability of type II error was zero, demonstrating that the sample was sufficient for the study findings.

\section{Discussion}

In this study, the heart rate was measured and the behavior of individuals with Down's Syndrome was observed during the dental appointment and compared with a control group of normotypical individuals. A significant increase in HR of DS participants was observed only at the time of prophylaxis. There was also a significant difference in behavior during the dental appointment; the prevalence of uncooperative behavior was higher among participants with DS.

The fact that the intragroup analysis of HR significantly varied during the dental appointment only for SG suggests that the dental appointment is a determining factor for the occurrence of such physiological alterations. Furthermore, during prophylaxis, median HR values were higher for SG than for CG. This result may be explained by the delay in the psychosocial, cognitive and emotional development of individuals with DS, who may present a more anxious response [14]. Individuals with DS may find it difficult to evaluate the invasive nature of dental treatment or understand the instructions and explanations given by the dentist, thus increasing their level of tension [15]. 
In $\mathrm{SG}$, a progressive increase in $\mathrm{HR}$ values was observed as the procedures progressed between $\mathrm{T} 1$ and T3, with a slight decrease at T4 (immediately after the end of prophylaxis). This increase may be related to the length of time and/or to the succession of the steps of the procedure adopted, which may increase fear and anxiety [16].

The highest values measured for HR were distinct between the groups. In SG, the highest values were measured at T3, whereas in CG, greater HR was observed at T4. This difference is probably related to differences in perception and manifestation of anxiety and stress-related to the procedure between the groups.

Regarding behavior analysis, we chose the Frankl Behavior-Rating Scale [12] because it is a functional and reliable method that quantifies the behavior into four categories. It is the main method used for this purpose and is currently used by several researchers [17-19].

When dichotomizing the sample in an uncooperative and cooperative group, it became clear how individuals with DS tend to be more uncooperative. There are no studies in the literature that support these findings. However, it is believed that a higher prevalence of uncooperative behavior associated with individuals with DS is justified by the fact that DS individuals have greater difficulty in understanding and weaker perception skills. They probably have exacerbated reactions of stress to procedures that are considered low invasive for the individuals who can correctly perceive the dental procedures [20].

The effects of dental appointments on physiological and behavioral parameters of individuals with DS are rarely reported in the literature. Some authors compared the behavior and HR of individuals with DS who underwent two different dental caries removal protocols [21]. The results of this study demonstrated that the dental appointment promoted more significant physiological changes in the DS group, with emphasis on the increase of HR and a higher occurrence of "tense" behavior, a classification equivalent to uncooperative in the behavioral scale adopted in this study. Our findings corroborated their findings.

A longitudinal study [22] demonstrated that the use of audiovisual resources was effective in reducing physiological changes in children (mean age $=7.1$ years) submitted to prophylaxis. However, they did not have a control group to compare their results. Another study, a systematic review and meta-analysis concluded that individuals with DS, when compared with their controls without DS, did not have significant HR variability at rest [23]. However, the literature remains unclear about the cardiovascular behavior of individuals with the syndrome in stressful situations, such as a dental appointment [4].

Medical and dental procedures are stressful conditions that trigger physiological changes of the fightor-flight type, an inherent human reaction to challenging situations [2,24-27]. The high prevalence of individuals with DS who have congenital cardiac alterations justifies the determination of potentially dangerous situations that can significantly alter cardiovascular parameters [1,28].

Due to the unavailability of a national, state or municipal database characterizing the population affected by DS, we could not calculate a sample to be representative of the entire population. Therefore, we used a non-probabilistic sample and selected at the level of a specialized health care center. CIES is funded by the government at a state level and is a referral centre for children with special needs. Thus, the generalization of the findings cannot be assumed for different populations with DS. However, pairing the study participants with a randomized control group strengthens the methodological rigor of the study.

The internal validity of the study was adequate because a single-examiner was trained and calibrated, avoiding possible measurement bias. The blind analysis of the results by an independent researcher reduced the risk of possible detection bias. Selection bias was avoided with the adoption of inclusion criterion, for both groups: participants who had previously been submitted to a dental appointment and received prophylaxis. 
As a final consideration of our study, we strongly recommend dentists to use behavioral management techniques in order to minimize cardiovascular changes in patients during a dental appointment. Individuals with DS, even during non-invasive procedures such as prophylaxis, have been shown to experience significant variations in HR. Further studies to evaluate physiological parameters changes related to dental treatment could be carried out by comparing dental procedures with other situations that induce cardiovascular or other changes.

\section{Conclusion}

The dental appointment resulted in significant HR variation in individuals with DS, unlike in individuals without DS. "During prophylaxis" was the only moment when a significant difference in HR was observed between groups. Participants with DS tend to be more uncooperative during the dental appointment than participants without DS.

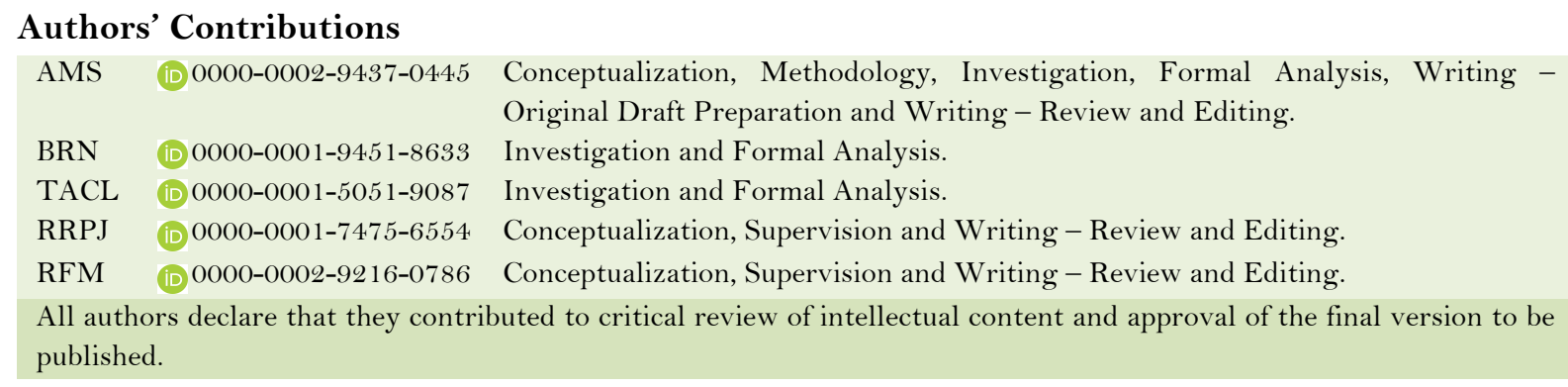

\section{Financial Support}

This study was financed in part by the Coordenação de Aperfeiçoamento de Pessoal de Nível Superior - Brasil (CAPES) Finance Code 001.

\section{Conflict of Interest}

The authors declare no conflict of interest.

\section{Acknowledgements}

The authors thank the dentist responsible for the treatment of the children, Dr. Regina Fátima Fernandes and Jonathan Spottiswoode for the translation of this manuscript.

\section{References}

[1] Goulart JCF, Pinheiro MD, Rodrigues RV, Santos FS, Martins AT, Scannavino FLF. Influence of anxiety on blood pressure and heart rate during dental treatment. Rev Odonto Cienc 2012; 27(1):31-5. https://doi.org/10.1590/S1980-65232012000100006

[2] Shim YS, Kim AH, Jeon EY, An SY. Dental fear \& anxiety and dental pain in children and adolescents: a systemic review. J Dent Anesth Pain Med 2015; 15(2):53-61. https://doi.org/10.17245/jdapm.2015.15.2.53

[3] Furlan NF, Gavião MB, Barbosa TS, Nicolau J, Castelo PM. Salivary cortisol, alpha-amylase and heart rate variation in response to dental treatment in children. J Clin Pediatr Dent 2012; 37(1):83-7.

[4] Nicolosi L, Lewin P, Winter G, Medina F, Carballo J, Martinez C, Rubio M. Comparative study of changes in arterial pressure and heart rate during dental treatment under local anesthesia in hypertensive patients versus normotensive patients. Acta Odontol Latinoam 2012; 25(3):318-23.

[5] Zhang C, Qin D, Shen L, Ji P, Wang J. Does audiovisual distraction reduce dental anxiety in children under local anesthesia? A systematic review and meta-analysis. Oral Dis 2019; 25(2):416-24. https://doi.org/10.1111/odi.12849

[6] Knegt NC, Evenhuis HM, Lobbezoo F, Schuengel C, Scherder EJA. Does format matter for comprehension of a facial affective scale and a numeric scale for pain by adults with Down syndrome? Res Dev Disabil 2013; 34(10):3442-8. https://doi.org/10.1016/j.ridd.2013.07.016 
[7] Morales-Demori R. Congenital heart disease and cardiac procedural outcomes in patients with trisomy 21 and Turner syndrome. Congenit Heart Dis 2017; 12(6):820-7. https://doi.org/10.1111/chd.12521

[8] Ribas GL. Evaluation of children's anxiety when submited to dental treatment. Arq Odontol 2006; 42(3):161-76.

[9] Possobon RF, Carrascoza KC, Moraes ABA, Costa JRAL. O tratamento odontológico como gerador de ansiedade. Psicol Estud 2007; 12(3):609-16. [In Portuguese]

[10] Aitken JC, Wilson S, Coury D, Moursi AM. The effect of music distraction on pain, anxiety and behavior in pediatric dental patients. Pediatr Dent 2002; 24(2):114-8.

[11] Topaloglu-Ak A, Eden E, Frencken JE. Perceived dental anxiety among schoolchildren treated through three caries removal approaches. J Appl Oral Sci 2007; 15(3):235-40. https://doi.org/10.1590/s1678-77572007000300015

[12] Frankl SN, Shiere FR, Fogels HR. Should the parent remain with the child in the dental operatory? ASDC J Dent Child 1962; 29:150-63.

[13] World Health Organization. Oral Health Surveys: Basic Methods. Geneva: WHO, 1997.

[14] Eickmann SH, Emond AM, Lima M. Evaluation of child development: beyond the neuromotor aspect. J Pediatr 2016; 92(3):S71-S83. https://doi.org/10.1016/j.jped.2016.01.007

[15] Duric NS, Assmus J, Gundersen D, Duric Golos A, Elgen IB. Multimodal treatment in children and adolescents with attention-deficit/hyperactivity disorder: a 6-month follow-up. Nord J Psychiatry 2017; 71(5):386-94. https://doi.org/10.1080/08039488.2017.1305446

[16] Cademartori MG, Costa VPP, Corrêa MB, Goettems ML. The influence of clinical and psychosocial characteristics on children behaviour during sequential dental visits: a longitudinal prospective assessment. Eur Arch Paediatr Dent 2019. https://doi.org/10.1007/s40368-019-00444-6.

[17] Al-Namankany A, Souza M, Ashley P. Evidence-based dentistry: analysis of dental anxiety scales for children. Br Dent J 2012; 212(5):2 19-22. https://doi.org/10.1038/sj.bdj.2012.174

[18] Aminabadi NA, Pourkazemi M, Babapour J, Oskouei SG. The impact of maternal emotional intelligence and parenting style on child anxiety and behavior in the dental setting. Med Oral Patol Oral Cir Bucal 2012; 17(6):108995. https://doi.org/10.4317/medoral.17839

[19] Suprabha BS, Rao A, Choudhary S, Shenoy R. Child dental fear and behavior: the role of environmental factors in a hospital cohort. J Indian Soc Pedod Prev Dent 201 1; 29(2):95-101. https://doi.org/10.4103/0970-4388.84679

[20] Lin CS. Pain catastrophizing in dental patients. J Am Dent Assoc 2013; 144(11):1244-51. https://doi.org/10.14219/jada.archive.2013.0052

[21] Guaré RO, Ciamponi AL, Romano MM. Behavioral and physiological changes in children with Down syndrome using mechanical and chemomechanical (Carisolv) caries removal methods. Spec Care Dentist 2008; 28(5):195-200. https://doi.org/10.1111/j.1754-4505.2008.00024.x

[22] Fakhruddin KS, El Batawi H, Gorduysus MO. Effectiveness of audiovisual distraction with computerized delivery of anesthesia during the placement of stainless steel crowns in children with Down syndrome. Eur J Dent 2017; 11(1):15. https://doi.org/10.4103/ejd.ejd_288_16

[23] Carvalho TD, Massetti T, Silva TDD, Crocetta TB, Guarnieri R, Vanderlei LCM, et al. Heart rate variability in individuals with Down syndrome - A systematic review and meta-analysis. Auton Neurosci 2018; 213:23-33. https://doi.org/10.1016/j.autneu.2018.05.006

[24] Seligman LD, Hovey JD, Chacon K, Ollendick TH. Dental anxiety: an understudied problem in youth. Clin Psychol Rev 2017; 55:25-40. https://doi.org/10.1016/j.cpr.2017.04.004

[25] Simon AK, Bhumika TV, Nair NS. Does atraumatic restorative treatment reduce dental anxiety in children? a systematic review and meta-analysis. Eur J Dent 2015; 9(2):304-9. https://doi.org/10.4103/1305-7456.156841

[26] Kilinç G, Akay A, Eden E, Sevinç N, Ellidokuz H. Evaluation of children's dental anxiety levels at a kindergarten and at a dental clinic. Braz. Oral Res 2016; 30(1):e72. https://doi.org/10.1590/1807-3107BOR-2016.vol30.0072

[27] Klingberg G, Broberg AG. Dental fear/anxiety and dental behaviour management problems in children and adolescents: a review of prevalence and concomitant psychological factors. Int J Paediatr Dent 2007; 17(6):391-406. https://doi.org/10.1111/j.1365-263X.2007.00872.x

[28] Dutra RM, Neves IL, Neves RS, Atik E, Santos UP. Peripheral oxygen saturation, heart rate, and blood pressure during dental treatment of children with cyanotic congenital heart disease. Clinics 2014; 69(5):314-8. https://doi.org/10.6061/clinics/2014(05)03 